\title{
Exercise training increases insulin-stimulated glucose disposal and GLUT4 (SLC2A4) protein content in patients with type 2 diabetes
}

\author{
D. J. O'Gorman • H. K. R. Karlsson • S. McQuaid · \\ O. Yousif • Y. Rahman • D. Gasparro $\cdot$ S. Glund • \\ A. V. Chibalin · J. R. Zierath · J. J. Nolan
}

Received: 26 April 2006 / Accepted: 8 August 2006/ Published online: 26 September 2006

(C) Springer-Verlag 2006

\begin{abstract}
Aims/hypothesis Exercise enhances insulin-stimulated glucose transport in skeletal muscle through changes in signal transduction and gene expression. The aim of this study was to assess the impact of acute and short-term exercise training on whole-body insulin-mediated glucose disposal and signal transduction along the canonical insulin signalling cascade.

Methods A euglycaemic-hyperinsulinaemic clamp, with vastus lateralis skeletal muscle biopsies, was performed at baseline and $16 \mathrm{~h}$ after an acute bout of exercise and shortterm exercise training (7 days) in obese non-diabetic $(n=7)$ and obese type 2 diabetic $(n=8)$ subjects.

Results Insulin-mediated glucose disposal was unchanged following acute exercise in both groups. Short-term exercise training increased insulin-mediated glucose disposal in obese type 2 diabetic $(p<0.05)$, but not in obese non-diabetic subjects. Insulin activation of (1) IRS1, (2) IRS2, (3) phosphotyrosine-associated phosphatidylinositol3 kinase activity and (4) the substrate of phosphorylated Akt, AS160, a functional Rab GTPase activating protein important for GLUT4 (now known as solute carrier family 2 [facilitated glucose transporter], member 4 [SLC2A4]) translocation, was unchanged after acute or chronic exercise
\end{abstract}

D. J. O'Gorman · S. McQuaid · O. Yousif · Y. Rahman •

D. Gasparro $\cdot$ J. J. Nolan $(\bowtie)$

Metabolic Research Unit, St James's Hospital, Trinity College,

Dublin, Ireland

e-mail: jnolan@stjames.ie

H. K. R. Karlsson • S. Glund • A. V. Chibalin · J. R. Zierath

Department of Molecular Medicine and Surgery,

Section of Integrative Physiology, Karolinska Institutet,

Stockholm, Sweden in either group. GLUT4 protein content was increased in obese type 2 diabetic subjects $(p<0.05)$, but not in obese non-diabetic subjects following chronic exercise.

Conclusions/interpretation Exercise training increased whole-body insulin-mediated glucose disposal in obese type 2 diabetic patients. These changes were independent of functional alterations in the insulin-signalling cascade and related to increased GLUT4 protein content.

Keywords Exercise · GLUT4 · Insulin · Obese ·

Type 2 diabetes

$\begin{array}{ll}\text { Abbreviations } \\ \text { AMPK } & \text { AMP-activated protein kinase } \\ \text { AS160 } & \text { substrate of phosphorylated Akt } \\ \text { DTT } & \text { dithiothreitol } \\ \text { GAP } & \text { GTPase activating protein } \\ \text { GIR } & \text { glucose infusion rate } \\ \text { PI3K } & \text { phosphatidylinositol 3-kinase } \\ V \mathrm{O}_{2 \text { peak }} & \text { peak oxygen uptake }\end{array}$

\section{Introduction}

Whole-body insulin-stimulated glucose disposal is reduced in obesity and type 2 diabetes $[1,2]$. Several lines of evidence suggest that decreased insulin-mediated glucose uptake in skeletal muscle is the primary defect in the aetiology of type 2 diabetes mellitus [1,3-5]. Defects in whole-body insulin-mediated glucose uptake in type 2 diabetic patients have been tracked to impairments in insulin signalling and GLUT4 (now known as solute carrier family 2 [facilitated glucose transporter], member 4 [SLC2A4]) translocation [6-8]. People with type 2 diabetes 
have decreased skeletal muscle IRS1 tyrosine phosphorylation and phosphatidylinositol 3-kinase (PI3K) activity following insulin stimulation in comparison with lean control subjects [9-11]. These changes are unrelated to reductions in protein levels of insulin signalling targets $[9$, 10] or GLUT4 protein content [12]. Thus, functional changes in the regulation of the insulin-signalling cascade are likely to contribute to decreased insulin-mediated glucose transport in skeletal muscle. Clearly any therapeutic approach that enhances insulin signalling or glucose uptake could provide a clinical benefit in the treatment of type 2 diabetes.

Exercise and diet are the cornerstones of type 2 diabetes prevention; however, the molecular mechanisms are unresolved. The repeated muscle contractions elicited during acute exercise enhance glucose transport and insulin sensitivity in healthy subjects directly in skeletal muscle $[13,14]$. In obese and type 2 diabetes subjects, acute exercise increases insulin receptor and IRS1 phosphorylation, but not PI3K activity or glucose disposal [2]. Chronic exercise training is also associated with changes in signal transduction and gene expression. In rodents, acute (1 day) and short-term ( 5 days) exercise training are associated with an increase in insulin signal transduction and glucose uptake in skeletal muscle [15]. Likewise in young healthy humans, short-term (7 days) exercise increases insulinmediated whole-body glucose disposal, PI3K signalling $[14,16]$ and GLUT4 protein content [17-22]. In contrast, in middle-aged insulin-resistant individuals, short-term exercise training ( 7 days) increases whole-body insulin-mediated glucose disposal independently of changes in phosphotyrosine-associated PI3K activity [23]. It is unclear whether exercise training improves insulin signalling defects in type 2 diabetic patients. However, in some cases improvements in whole-body glucose disposal can be achieved independently of changes in insulin signalling, indicating that improvements in components distal to the cascade contribute to the exercise-mediated increases in glucose disposal.

Insulin signalling distal to PI3K is as yet incompletely characterised. A recently identified substrate of phosphorylated Akt (AS160) is implicated in the translocation of the GLUT4 vesicle to the plasma membrane [24]. Little is known of the physiological regulation of AS160 in human skeletal muscle. AS160 contains a GTPase activating protein (GAP) homology domain, which has been shown to regulate the GTPase activity of certain Rab proteins in vitro [25]. Studies in cultured 3T3-L1 adipocytes reveal that phosphorylation of AS160 by Akt is likely to inhibit its GAP activity, that as a consequence, the GTP form of a Rab protein is elevated, and that this elevation in turn increases GLUT4 vesicle movement to, and/or fusion with, the plasma membrane $[24,26,27]$. Interestingly, AS160 is also phosphorylated in response to muscle contraction, and as such may serve as a key intermediary in insulin-induced, as well as contraction-induced glucose transport [28]. Thus, exercise-induced changes in AS160 phosphorylation may contribute to improvements in insulin-stimulated glucose disposal.

The purpose of this study was to determine the impact of acute ( 1 day) and chronic (7 days) exercise training on whole-body insulin-mediated glucose disposal and insulin signalling through PI3K and the novel AS160 in skeletal muscle from obese non-diabetic and obese type 2 diabetic subjects. We hypothesised that exercise-induced improvements in insulin sensitivity could be associated with functional changes in the insulin-signalling cascade and/or GLUT4 protein levels.

\section{Subjects and methods}

\section{Subjects}

The protocol was approved by the institutional ethics committee of St James's Hospital and written informed consent was obtained from all subjects prior to participation. The groups comprised eight (six men and two women) obese type 2 diabetic subjects and seven (six men and one woman) weight-matched obese non-diabetic subjects with normal glucose tolerance. Glycaemic control for the type 2 diabetic subjects was maintained by diet alone (two subjects) or diet plus metformin (six subjects). All subjects had been on stable treatment for the previous 6 months and refrained from taking medication on the morning of the clamp. Peak oxygen uptake $\left(V \mathrm{O}_{2 \text { peak }}\right)$ was determined by indirect calorimetry (SensorMedics, Yorba Linda, CA, USA) using an incremental bicycle ergometer protocol. A 3-hour OGTT was used to confirm glucose tolerance.

\section{Experimental design}

Baseline insulin sensitivity was determined by a 2-h euglycaemic-hyperinsulinaemic clamp. The following afternoon (day 2), subjects reported to the Metabolic Research Unit and exercised on a stationary bicycle ergometer for $60 \mathrm{~min}$ at $75 \% V_{2} \mathrm{O}_{2 \text { peak }}$. A euglycaemic-hyperinsulinaemic clamp was repeated $16 \mathrm{~h}$ later (day 3 ) to assess the effects of the acute bout of exercise. Subjects then exercised on seven consecutive days for $1 \mathrm{~h}$ at $75 \% \mathrm{VO}_{2 \text { peak }}$ (days 4-10). On day $11,16 \mathrm{~h}$ after the last training session, subjects repeated the euglycaemic-hyperglycaemic clamp to assess the impact of short-term exercise training on insulin sensitivity. 
Euglycaemic-hyperinsulinaemic clamp

Dietary advice was provided to the subjects to ensure they consumed a balanced, energy-sufficient diet for 2 days prior to the clamp. Subjects reported to the Metabolic Research Unit at $08.00 \mathrm{~h}$, following a 10-h overnight fast. A polyethylene cannula was inserted retrogradely into a dorsal hand vein for blood sampling and into an antecubital vein for infusion of insulin and glucose. Following baseline blood samples, a muscle biopsy was taken from the mid-vastus lateralis muscle under local anaesthesia using a Bergstrom needle. An area of skin was anaesthetised with $1 \%$ lignocaine and a small $(0.5 \mathrm{~cm})$ incision made. The biopsy needle was inserted into the muscle and approximately $50 \mathrm{mg}$ of tissue removed. Muscle samples were snap-frozen in liquid nitrogen and stored at $-80^{\circ} \mathrm{C}$ for subsequent analysis. A primed continuous $40 \mathrm{mU} \mathrm{m}^{-2} \mathrm{~min}^{-1}$ insulin infusion was started and plasma glucose was clamped at $5.0 \pm$ $0.5 \mathrm{mmol} / \mathrm{l}$ with a variable glucose infusion $(20 \%$ dextrose) for $2 \mathrm{~h}$. Blood samples for glucose and insulin were drawn at 5- and 15-min intervals, respectively. A second biopsy was taken at $120 \mathrm{~min}$.

Exercise training protocol

Subjects exercised at $\sim 75 \% V^{2 \text { peak }}$ for $1 \mathrm{~h}$ on a stationary cycle ergometer (Fig. 1). The intensity was determined from the heart rate ( \pm 5 beats per min) corresponding to $75 \%$ $V \mathrm{O}_{2 \text { peak }}$, as measured by indirect calorimetry. Blood pressure and heart rate were monitored before, during and after exercise.

\section{Blood analysis}

Serum insulin was measured with a commercially available fluoroimmunoassay (Delphia; Perkin Elmer, Wallac, Turku, Finland). Plasma glucose was measured using a glucose oxidase method (Beckman, Fullerton, CA, USA) and $\mathrm{HbA}_{1 \mathrm{c}}$ was measured by HPLC using an autoanalyser (Menarini Diagnostics, Florence, Italy). Plasma cholesterol and triacylglycerol were measured using enzymatic methods (Roche Diagnostics, Mannheim, Germany). Plasma HDL-cholesterol and LDL-cholesterol were measured directly by enzymatic methods (Randox Laboratories, Crumlin, Co. Antrim, UK).

\section{Muscle analysis}

Approximately $50 \mathrm{mg}$ of muscle tissue was lyophilised overnight. Under a microscope samples were dissected free of visible blood, connective tissue and fat, and then weighed and homogenised using a motorised pestle in

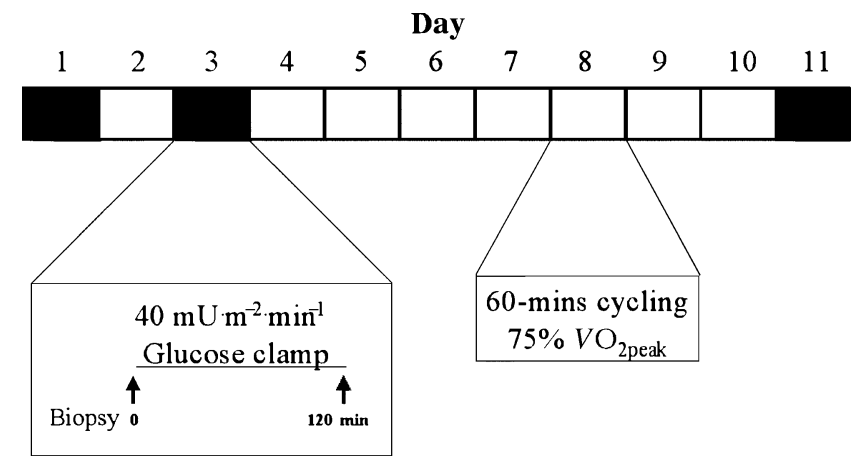

Fig. 1 Schematic representation of the study design

buffer (137 mmol/1 NaCl, $2.7 \mathrm{mmol} / 1 \mathrm{KCl}, 1 \mathrm{mmol} / 1 \mathrm{MgCl}_{2}$, $0.5 \mathrm{mmol} / 1 \mathrm{Na}_{3} \mathrm{VO}_{4}, 1 \%$ Triton $\mathrm{X}-100,10 \%$ glycerol,

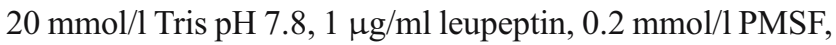
$10 \mathrm{mmol} / 1 \mathrm{NaF}, 1 \mu \mathrm{g} / \mathrm{ml}$ aprotinin, $1 \mathrm{mmol} / 1 \mathrm{EDTA}$, $5 \mathrm{mmol} / \mathrm{l} \mathrm{Na}$ pyrophosphate, $1 \mathrm{mmol} / 1$ benzamidine). Samples were rotated at $4^{\circ} \mathrm{C}$ for $30 \mathrm{~min}$ and then centrifuged at $12,000 \mathrm{~g}$ for $15 \mathrm{~min}$. A commercially available colorimetric assay using the Bradford protocol was used to determine protein content (Bio-Rad, Richmond, CA, USA).

Phosphatidylinositol 3-kinase activity

Aliquots of the supernatant fraction $(600 \mu \mathrm{g}$ of protein) were immunoprecipitated overnight $\left(4^{\circ} \mathrm{C}\right)$ with either anti-IRS1, anti-IRS2 or anti-phosphotyrosine antibodies (Upstate Biotechnology, Lake Placid, NY, USA) coupled to protein-A-sepharose (Sigma-Aldrich, St Louis, MO, USA). The immune complexes were washed three times in homogenate buffer, twice in buffer A $(500 \mathrm{mmol} / 1 \mathrm{LiCl}$, $100 \mathrm{mmol} / 1$ Tris $\mathrm{pH} 8.0$ ) and once in buffer $B$ (150 mmol/1 NaCl, $1 \mathrm{mmol} / 1$ EDTA, $10 \mathrm{mmol} / 1$ Tris $\mathrm{pH}$ 7.6). Samples were resuspended in $20 \mathrm{mmol} / 1$ Hepes $\mathrm{pH}$ 7.3, $1 \mathrm{mmol} / 1$ dithiothreitol (DTT) and $5 \mathrm{mmol} / 1 \mathrm{MgCl}_{2}$. The beads were resuspended in $20 \mu$ l kinase assay buffer (20 mmol/1 Hepes pH 7.3, 20 mmol/1 $\beta$-glycerophosphate $\mathrm{pH} 7.2,5 \mathrm{mmol} / \mathrm{l} \mathrm{Na}$ pyrophosphate, $30 \mathrm{mmol} / 1 \mathrm{NaCl}$, $1 \mathrm{mmol} / 1 \mathrm{DTT}, 20 \mu \mathrm{g} / \mathrm{sample}$ phosphatidylinositol (Avanti Polar Lipids, Alabaster, AL, USA), $740 \mathrm{kBq}$ per reaction $\left[\gamma_{-}{ }^{32} \mathrm{P}\right]$ ATP and $\left.12 \mu \mathrm{mol} / 1 \mathrm{ATP}\right)$. After $15 \mathrm{~min}$ the reaction was stopped by adding $20 \mu \mathrm{l}$ of hydrochloric acid ( $8 \mathrm{~mol} / \mathrm{l}$ ) and the phosphatidylinositol 3-phosphate extracted with $160 \mu$ l of methanol-chloroform $(1: 1, \mathrm{v} / \mathrm{v})$. The reaction products were separated by thin layer chromatography (Silica Gel 60; Merck, Darmstadt, Germany). The radioactivity incorporated into PI3K was quantified by a phosphor imager (Image Reader BAS-1800 II; Fujifilm, Düsseldorf, Germany) and the results normalised to a liver standard. 
Western blot analysis

Protein content of GLUT4 and phosphorylation of AS160 were determined. A portion of muscle lysate $(40 \mu \mathrm{g}$ protein) was mixed in Laemmli buffer $\mathrm{pH} 6.8(20 \%$ glycerol, $62.5 \mathrm{mmol} / 1$ Tris-HCl, 2\% SDS, $0.00125 \%$ bromophenol blue, $2 \% \beta$-mercaptoethanol). The samples were separated by SDS-PAGE and transferred to polyvinylidene difluoride membrane. Non-specific binding was blocked in a $5 \%$ milk/TBST $(10 \mathrm{mmol} / 1$ Tris $\mathrm{pH} 7.5$, $100 \mathrm{mmol} / 1 \mathrm{NaCl}, 0.1 \%$ Tween 20 ) for $2 \mathrm{~h}$ and incubated overnight with anti-GLUT4 antibody (Biogenesis, Poole, UK) or anti-phospho-(Ser/Thr) Akt substrate (PAS) antibodies (Cell Signalling Technology, Beverly, MA, USA). The membrane was washed in TBST, incubated with appropriate secondary horseradish peroxidase-conjugated antibodies, visualised with enhanced chemiluminescence reagents (Amersham, Arlington Heights, IL, USA) and quantified using densitometry and molecular analysis software (Bio-Rad).

Statistical analysis

Data are presented as mean \pm standard error. Data not normally distributed were log transformed. Two-way ANOVA and two-way repeated-measures ANOVA were used to determine significant main effects and interactions. A Student-Newman-Keuls post hoc test was used to identify specific mean differences. A Student's $t$ test and a paired $t$ test were used to determine significant differences within and between groups. A Pearson product moment correlation was used to determine relationships between variables. Statistical significance was accepted at the $p<0.05$ level of confidence for all variables.

\section{Results}

\section{Subject characteristics}

As shown in Table 1, fasting blood glucose was greater in the obese type 2 diabetes subjects $(p<0.05)$ and decreased following exercise training $(10.1 \pm 1.1$ vs $8.6 \pm 0.7 \mathrm{mmol} / \mathrm{l}, p$ $<0.05$ ). Fasting blood glucose was unchanged in the obese non-diabetic subjects following exercise training. Peak oxygen consumption was similar between groups, and body weight was unchanged following the exercise protocol. Subjects exercised at a similar heart rate $(130 \pm 4$ vs $132 \pm 6$ beats per min for the obese type 2 diabetic vs obese non-diabetic subjects, NS). Total cholesterol, HDLand LDL-cholesterol were within the normal range and similar between groups. Serum triacylglycerol was signif-
Table 1 Physical and metabolic descriptive characteristics

\begin{tabular}{|c|c|c|}
\hline & $\begin{array}{l}\text { Obese } \\
(n=7)\end{array}$ & $\begin{array}{l}\text { Type } 2 \text { diabetic } \\
(n=8)\end{array}$ \\
\hline Age (years) & $47.7 \pm 3.9$ & $44.6 \pm 2.2$ \\
\hline Weight (kg) & $100.9 \pm 5.5$ & $106.7 \pm 4.0$ \\
\hline Height (m) & $1.75 \pm 0.01$ & $1.73 \pm 0.04$ \\
\hline BMI $\left(\mathrm{kg} / \mathrm{m}^{2}\right)$ & $32.9 \pm 2.1$ & $35.8 \pm 1.9$ \\
\hline \multicolumn{3}{|l|}{ Blood pressure (mmHg) } \\
\hline Systolic & $129 \pm 6$ & $138 \pm 2$ \\
\hline Diastolic & $87 \pm 3$ & $84 \pm 5$ \\
\hline Fasting glucose (mmol/l) & $5.5 \pm 0.2$ & $10.1 \pm 1.1^{\mathrm{a}}$ \\
\hline 2-h OGTT glucose (mmol/l) & $5.9 \pm 0.8$ & $17.4 \pm 3.3$ \\
\hline Fasting insulin (pmol/1) & $63 \pm 18$ & $58 \pm 7.8$ \\
\hline $\mathrm{HbA}_{1 \mathrm{c}}(\%)$ & $5.6 \pm 0.2$ & $7.2 \pm 0.5^{\mathrm{a}}$ \\
\hline Triacylglycerol (mmol/l) & $1.3 \pm 0.3$ & $2.7 \pm 0.4^{\mathrm{a}}$ \\
\hline Total cholesterol (mmol/l) & $4.6 \pm 0.3$ & $5.1 \pm 0.2$ \\
\hline HDL-cholesterol (mmol/1) & $1.1 \pm 0.1$ & $1.2 \pm 0.1$ \\
\hline LDL-cholesterol (mmol/l) & $2.8 \pm 0.4$ & $2.6 \pm 0.1$ \\
\hline Peak heart rate (beats per min) & $163 \pm 6$ & $162 \pm 5$ \\
\hline$V \mathrm{O}_{2 \text { peak }}\left(\mathrm{ml} \mathrm{kg}^{-1} \min ^{-1}\right)$ & $21.3 \pm 2.7$ & $24.5 \pm 2.5$ \\
\hline
\end{tabular}

Data are presented as mean \pm SE. ${ }^{\text {a }}$ Significantly different from obese non-diabetic subjects, $p<0.05$

$V \mathrm{O}_{2 \text { peak }}$, peak oxygen uptake

icantly greater in the obese type 2 diabetic subjects. BMI and blood pressure were similar between the groups.

Insulin action

The baseline glucose infusion rate (GIR) increased in obese non-diabetic subjects, though not significantly, from $4.5 \pm$ $1.4 \mathrm{mg} \mathrm{kg}^{-1} \mathrm{~min}^{-1}$ at baseline, to $5.2 \pm 1.5 \mathrm{mg} \mathrm{kg}^{-1} \mathrm{~min}^{-1}$ after a single bout of exercise and $6.6 \pm 1.4 \mathrm{mg} \mathrm{kg} \mathrm{min}^{-1}$ following 7 days of exercise (Fig. 2). GIRs in the obese type 2 diabetic subjects increased significantly after 7 days of exercise, but not after the single exercise bout $(2.6 \pm 0.7$ vs $3.2 \pm 0.8$ vs $4.1 \pm 1.0 \mathrm{mg} \mathrm{kg}^{-1} \mathrm{~min}^{-1}$, for baseline, acute and 7 days of exercise). The baseline GIR for both groups was positively correlated with $V \mathrm{O}_{2 \text { peak }}(r=0.56, p<0.05)$ and negatively correlated with BMI $(r=-0.69, p<0.01)$ and with the increase in the GIR following 7 days of training $(r=-0.63, p=0.02)$.

Insulin-stimulated PI3K activity

\section{IRS1-associated PI3K activity}

Insulin infusion increased IRS1-associated PI3K activity in both groups (2.7 \pm 0.4 and $1.9 \pm 0.2$-fold for the obese type 2 diabetic and obese non-diabetic subjects respectively, $p<$ 0.05 ) (Table 2). The insulin-stimulated response was greater in the obese type 2 diabetic subjects than in the obese nondiabetic subjects $(p<0.05)$. Insulin-stimulated PI3K was 
Fig. 2 Glucose infusion rates for the obese type 2 diabetic and obese non-diabetic subjects at baseline ( ) and following 1 day ( $\square$ ) and 7 days ( of exercise. Data are expressed as mean \pm SE. $* p<0.05$ for difference from baseline

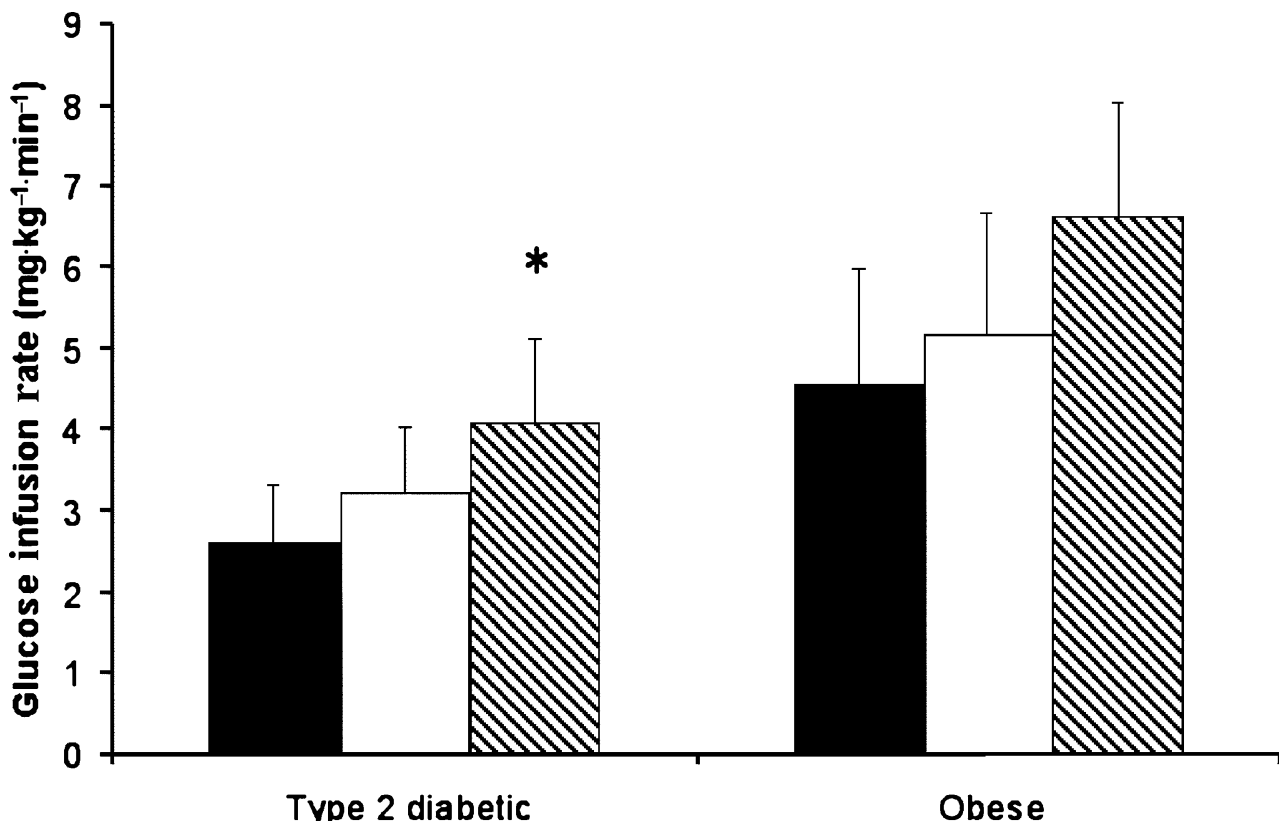

decreased in the obese type 2 diabetic subjects following 1 day $(1.9 \pm 0.2$-fold, $p<0.05)$ and 7 days of exercise $(1.5 \pm$ 0.4 -fold, $p<0.05$ ), without any change in the obese nondiabetic subjects. This was associated with a gradual increase in basal IRS1-associated PI3K activity and a gradual decrease in insulin-stimulated activity (Fig. 3a).

\section{IRS2-associated PI3K activity}

Insulin infusion did not significantly increase IRS2-associated PI3K activity at baseline in the obese non-diabetic or type 2 diabetic subjects (Fig. 3b). Neither 1 day nor 7 days of exercise subsequently resulted in a change in basal or insulin-stimulated IRS2-associated PI3K activity.

\section{Phosphotyrosine-associated PI3K activity}

Sufficient sample material was available to assess phosphotyrosine-associated PI3K activity in five of the eight obese type 2 diabetic subjects and five of the seven obese non-diabetic subjects. Insulin infusion did not significantly increase phosphotyrosine-associated PI3K activity in the obese non-diabetic or type 2 diabetic subjects at baseline or following 1 day or 7 days of exercise (Fig. 3c). Insulinstimulated phosphotyrosine-associated PI3K activity was greater in the obese non-diabetic subjects at baseline $(0.87 \pm$ 0.07 vs $1.35 \pm 0.23$-fold, $p<0.05$ ).

\section{AS160 phosphorylation}

Insulin-stimulated Akt phosphorylates a $160-\mathrm{kDa}$ substrate termed AS160. Before exercise training, insulin increased AS160 phosphorylation in both groups $(1.5 \pm 0.5$ vs $1.9 \pm 0.5$ for the obese type 2 diabetic and obese non-diabetic subjects, respectively). Insulin-stimulated AS160 phosphorylation was unaltered following either a single bout of exercise or short-term exercise training in both groups (Fig. 4).

Table 2 IRS1-, IRS2- and phosphotyrosine-associated PI3K activity before and after insulin infusion at baseline, and following 1 day and 7 days of exercise in obese type 2 diabetic and obese non-diabetic subjects

\begin{tabular}{|c|c|c|c|c|c|c|c|}
\hline & & \multicolumn{2}{|c|}{ IRS1-associated PI3K } & \multicolumn{2}{|c|}{ IRS2-associated PI3K } & \multicolumn{2}{|c|}{ PTyr-associated PI3K } \\
\hline & & Pre & Post & Pre & Post & Pre & Post \\
\hline \multirow[t]{2}{*}{ Baseline } & $\mathrm{T} 2 \mathrm{DM}$ & $0.84 \pm 0.15$ & $2.20 \pm 0.55^{\mathrm{a}}$ & $0.33 \pm 0.04$ & $0.45 \pm 0.07$ & $1.05 \pm 0.26$ & $0.86 \pm 0.15$ \\
\hline & Obese & $0.76 \pm 0.06$ & $1.39 \pm 0.11^{\mathrm{a}}$ & $0.44 \pm 0.07$ & $0.43 \pm 0.07$ & $0.76 \pm 0.11$ & $1.09 \pm 0.28$ \\
\hline \multirow[t]{2}{*}{1 day exercise } & $\mathrm{T} 2 \mathrm{DM}$ & $0.93 \pm 0.16$ & $1.61 \pm 0.19^{\mathrm{a}}$ & $0.36 \pm 0.06$ & $0.41 \pm 0.07$ & $0.95 \pm 0.16$ & $1.08 \pm 0.15$ \\
\hline & Obese & $0.70 \pm 0.07$ & $1.60 \pm 0.12^{\mathrm{a}}$ & $0.45 \pm 0.08$ & $0.49 \pm 0.06$ & $1.06 \pm 0.23$ & $1.11 \pm 0.26$ \\
\hline \multirow[t]{2}{*}{7 days exercise } & $\mathrm{T} 2 \mathrm{DM}$ & $0.97 \pm 0.17$ & $1.34 \pm 0.21$ & $0.41 \pm 0.04$ & $0.40 \pm 0.04$ & $1.01 \pm 0.18$ & $1.12 \pm 0.34$ \\
\hline & Obese & $0.82 \pm 0.13$ & $1.54 \pm 0.30^{\mathrm{a}}$ & $0.44 \pm 0.07$ & $0.48 \pm 0.08$ & $1.00 \pm 0.17$ & $0.99 \pm 0.23$ \\
\hline
\end{tabular}

Data are presented as mean $\pm \mathrm{SE}$ (arbitrary units). ${ }^{\text {a }}$ Significantly different from pre-infusion, $p<0.05 . T 2 D M$ : type 2 diabetes;

PTyr: phosphotyrosine 


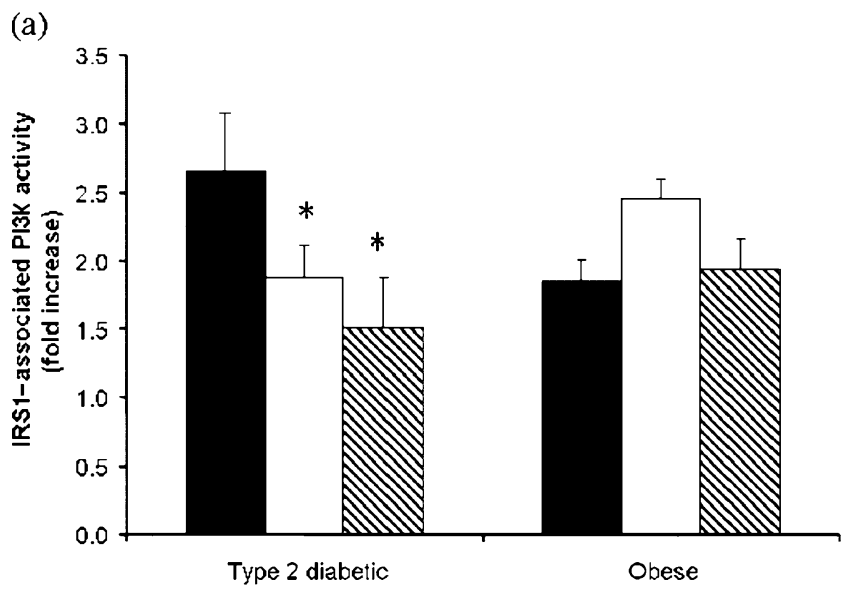

(b)

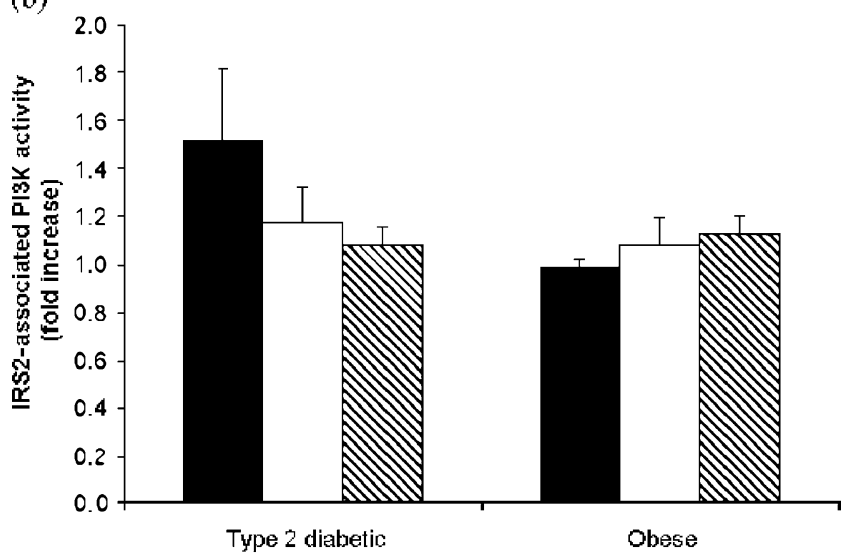

(c)

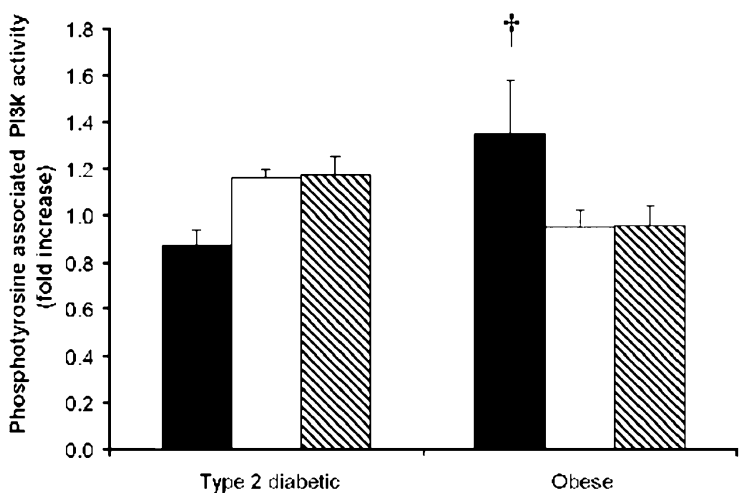

Fig. 3 PI3K activity from the euglycaemic-hyperinsulinaemic clamp

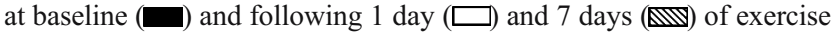
in obese type 2 diabetic and obese non-diabetic subjects. Bars represent the fold change in activity (insulin infusion/fasting), in response to the insulin infusion, for (a) IRS1-associated, (b) IRS2associated and (c) phosphotyrosine-associated PI3K activity. Data are presented as mean \pm SE. ${ }^{*} p<0.05$ for difference from baseline

\section{GLUT4 protein content}

Skeletal muscle GLUT4 protein content in obese type 2 diabetic subjects was unaltered after acute exercise and increased following short-term exercise training $(0.20 \pm$ $0.06,0.22 \pm 0.05,0.35 \pm 0.10$ arbitrary units for baseline, acute and 7 days of exercise, respectively) (Fig. 5). This corresponds to an $87 \%$ increase in GLUT4 protein content following 7 days of exercise. Protein content of GLUT4 in the obese non-diabetic subjects was unaltered following either acute exercise or 7 days of training $(0.31 \pm 0.06,0.38 \pm$ $0.07,0.35 \pm 0.07$ arbitrary units for baseline, acute and 7 days of exercise, respectively) (Fig. 5).

\section{Discussion}

Exercise is the cornerstone of type 2 diabetes prevention and treatment. The results from the present study provide molecular evidence for the beneficial effects of exercise on insulin sensitivity in people with type 2 diabetes. Following 7 days of exercise training, fasting blood glucose and whole-body insulin-stimulated glucose disposal were significantly improved in the obese type 2 diabetic subjects. The exercise-induced improvements in whole-body insulin sensitivity were independent of changes in insulin signalling. Our results provide evidence that exercise-induced improvements in whole-body insulin sensitivity in obese type 2 diabetic patients occurs in concert with an increase in the total amount of GLUT4 in skeletal muscle.

In healthy young subjects, insulin-mediated glucose disposal is enhanced for a period of up to 2 days following a single bout of exercise [29]. In the immediate aftermath of exercise, IRS1-associated PI3K activity [30] and GLUT4 protein content [31] are unaltered. The muscle glycogen concentration and glycogen synthase activity after exercise contribute to the regulation of glucose transport and disposal in an insulin-independent manner [32]. Thus, exercise has been considered to have positive effects on whole-body glucose homeostasis, and it has been suggested that these effects on metabolism bypass defects in insulin signalling in type 2 diabetes [6].

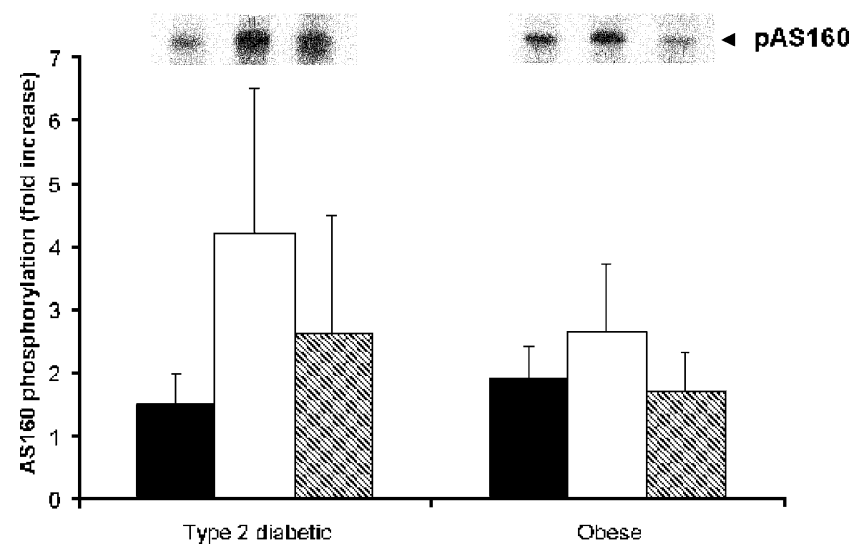

Fig. 4 AS160 phosphorylation for the obese type 2 diabetic and obese non-diabetic subjects at baseline $(\square)$ and following 1 day $(\square)$ and 7 days of exercise. Bars represent the fold change in phosphorylation (insulin infusion/fasting) in response to the insulin infusion. Data are expressed as mean \pm SE. pAS160, phosphorylated AS160 


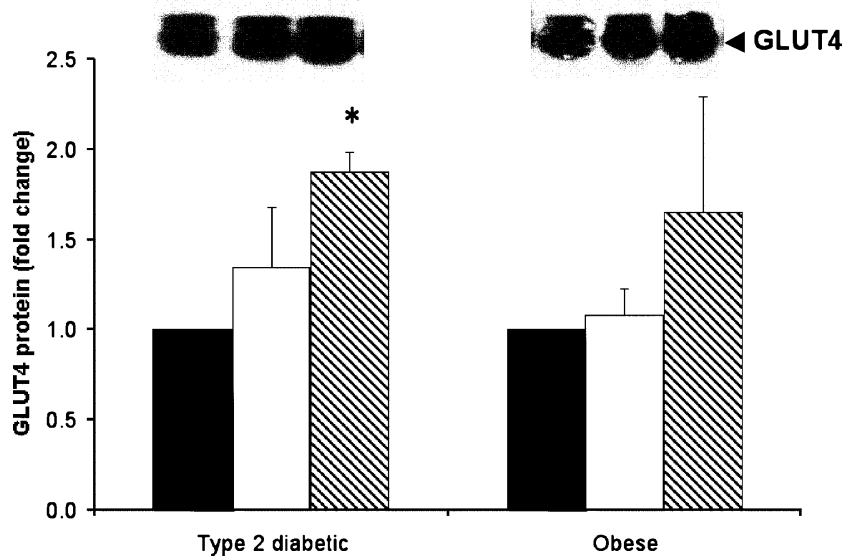

Fig. 5 Total GLUT4 protein content in obese type 2 diabetic and obese non-diabetic subjects at baseline $(\square)$ and following 1 day $(\square)$ and 7 days ( of exercise. Data are expressed as mean \pm SE fold change from baseline. ${ }^{*} p<0.05$ for difference from baseline

In insulin-resistant humans, whole-body glucose disposal was increased between 12 and $48 \mathrm{~h}$ after an acute bout of exercise in some [33, 34], but not all [2] studies. Here we report that whole-body insulin-mediated glucose disposal was unaltered in obese non-diabetic and obese type 2 diabetic subjects $16 \mathrm{~h}$ after $1 \mathrm{~h}$ of cycle ergometer exercise performed at $75 \% \mathrm{VO}_{2 \text { peak }}$. Our results are consistent with previous findings [2]. Given the complex pathology of insulin resistance, individuals with severe insulin resistance or type 2 diabetes may need to perform exercise training for a longer duration to achieve the metabolic adaptations to exercise. For example, insulin-mediated glucose disposal has been shown to be increased following varying periods of exercise training in studies of insulin-resistant subjects $[23,24,35]$. Moreover, insulin-mediated glucose disposal is increased following 14 weeks of exercise-induced weight loss in obese subjects [35] or after chronic exercise training in either insulin-resistant individuals [23, 34] or type 2 diabetic patients [13]. Our results demonstrate that 7 days of exercise training increased insulin-mediated glucose disposal in obese type 2 diabetic but not in obese nondiabetic insulin-resistant subjects. While insulin-mediated glucose disposal was not significantly increased in the obese non-diabetic subjects, the positive trend for a $45 \%$ increase in glucose uptake was of a similar magnitude to that reported earlier [23]. We noted an inverse relationship between baseline insulin sensitivity and the magnitude of change in glucose disposal following 7 days of training ( $r=$ $-0.63, p=0.02$ ), indicating that subjects with the greatest degree of insulin resistance had the greatest relative response.

We hypothesised that exercise training in the obese nondiabetic and obese type 2 diabetic subjects would increase insulin action on components of the canonical insulin signalling cascade. Exercise training for 7 days [14],
10 weeks [36] or longer [16] is associated with improved whole-body insulin-mediated glucose disposal in healthy individuals and these improvements have been attributed to enhanced intracellular signalling via PI3K activity $[14,16]$. However, in the present cohort, the enhanced insulin sensitivity in the obese type 2 diabetic subjects was independent of changes in IRS1-, IRS2- and phosphotyrosine-associated PI3K activity. These results are in contrast to the positive relationship between insulin-mediated glucose disposal and IRS1-associated PI3K activity in healthy individuals [14, 16], and consistent with studies in other insulin-resistant individuals [23]. The decrease in IRS1-associated PI3K activity in the type 2 diabetic group was unexpected. The insulin dose or the timing of the biopsy during the clamp may have influenced the outcome of these results. However, other studies provide evidence for a decrease or downward trend in insulin-stimulated PI3K activity following exercise $[2,37]$. While this may be due to IRS1-independent PI3K activity, or PI3K-independent mechanisms, the insulin infusion failed to increase IRS2-associated PI3K activity. IRS2 appears to be unnecessary for insulin- or exercise-stimulated glucose transport in skeletal muscle [38]. IRS2 protein content is unaltered in type 2 diabetic subjects compared to insulin-sensitive control subjects, but insulin action to promote the association of IRS2 and p85 is impaired [2]. Since phosphotyrosine-associated PI3K was unaltered after exercise, our results suggest that the training protocol was unable to reverse the inhibitory effects of protein phosphatases or serine phosphorylation, which have previously been shown to impair insulin action at the level of IRS1 and PI3K [39, 40]. PI3K-independent pathways or changes in the subunit regulation of PI3K may also influence the activity of the enzyme; however, this hypothesis has not been tested.

Investigation of the regulation of the insulin-signalling cascade proximal to PI3K has yielded inconsistent findings following exercise. An acute bout of exercise increased insulin receptor and IRS1 phosphorylation in obese and type 2 diabetic subjects without a change in IRS1associated PI3K activity or insulin-mediated glucose disposal [2]. However, in obese Zucker rats, glucose uptake is increased without a change in IRS1 phosphorylation or PI3K activity following 7 weeks of training [41]. Thus, enhanced signalling through PI3K cannot explain the changes in glucose disposal following short-term exercise in the obese non-diabetic subjects studied here. The contribution of PI3K to increased glucose disposal should be questioned. Glucose disposal rates are unaffected in 3T3-L1 adipocytes when PI3K activity is decreased by pretreatment with platelet-derived growth factor [42] or in cells overexpressing IRS1 interacting domains [43]. Therefore, glucose disposal rates can be maintained in the absence of effective PI3K signalling. Changes in more distal steps in 
the insulin signalling cascade or changes in GLUT4 protein may account for the improvements in skeletal muscle insulin sensitivity.

The increase in glucose disposal following exercise may be distal to PI3K and related to the translocation or docking of the GLUT4 vesicle. We measured the effect of exercise on insulin activation of AS160, a functional Rab GAP [25] that has been shown to regulate insulinstimulated GLUT4 translocation in 3T3-L1 adipocytes [24]. AS160 phosphorylation has been reported to be increased in rat skeletal muscle in response to insulin or contractile activity [28]. In young healthy human male subjects, AS160 phosphorylation is increased following an acute bout of endurance exercise, despite no change in Akt phosphorylation at $\mathrm{Thr}^{308}$ [44]. As full activation of Akt requires phosphorylation of $\mathrm{Ser}^{473}$ and $\mathrm{Thr}^{308}$, AS160 phosphorylation may be independent of Akt following endurance exercise. More recent work using $\alpha 2$ AMPactivated protein kinase $(A M P K)$ knock-out mice implicates AS160 as a substrate of AMPK [45]. Taken together, these results suggest that AS160 phosphorylation is differentially regulated by insulin and exercise. In type 2 diabetic subjects, AS160 phosphorylation in skeletal muscle is lower during insulin infusion [46] and was unresponsive to low-intensity exercise or rosiglitazone treatment, despite increased insulin-mediated glucose disposal [47]. Here we report that after moderate/highintensity exercise, insulin-stimulated AS160 phosphorylation is unchanged in obese non-diabetic or obese type 2 diabetic subjects. This finding confirms the observation that functional changes in the insulin-signalling cascade, even steps distal to PI3K, do not occur in response to short-term exercise training in obese and type 2 diabetes groups. Therefore, changes in gene expression may be responsible for the exercise-induced adaptations on skeletal muscle insulin sensitivity.

Skeletal muscle contraction is an important regulator of gene expression. In female Wistar rats, IRS1 protein content is decreased after 5 days of exercise training despite increased IRS1 phosphorylation and IRS1-associated PI3K activity [15], suggesting that exercise training may result in either increased rates of IRS1 protein degradation or decreased rates of protein synthesis. Cross-sectional analysis of endurance trained and untrained subjects revealed that the protein levels of the insulin receptor, IRS1 and IRS2 were $44 \%, 57 \%$ and $77 \%$ lower in trained versus untrained subjects [17]. Even following short-duration exercise training in young healthy subjects, gene expression of the insulin receptor or IRS1 is unchanged [48]. Therefore, exercise-mediated changes in the expression of the insulin receptor or IRS1 are unlikely to contribute to increased glucose disposal in the type 2 diabetic group following exercise. For a limited number of subjects $(n=4$ obese, $n=3$ obese type 2 diabetic), we had sufficient sample material to assess AS160 protein content. Our preliminary results suggest that AS160 protein levels were unaltered after 1 or 7 days exercise training in obese or obese type 2 diabetic subjects. AS160 protein content in skeletal muscle has previously been reported to be similar between type 2 diabetic and non-diabetic subjects, whereas insulin action on this target was reduced [46]. However, changes in GLUT4 protein may account for improved insulin-mediated glucose disposal.

In human muscle tissue, GLUT4 content is similar between healthy, insulin-resistant and type 2 diabetic individuals [12]. While GLUT4 protein levels are unaltered during the development of insulin resistance, expression levels are increased following exercise training [19, 20, 22]. Sixteen hours after an acute bout of exercise, GLUT4 mRNA was increased in type 2 diabetic subjects [22]. Moreover, with short-term exercise training, GLUT4 content in muscle is also increased [19, 20]. After 7 to 10 days of exercise training GLUT4 protein content increased by $98 \%$ in healthy individuals [19]. Here we report that short-term exercise training increases GLUT4 protein by $87 \%$ in obese type 2 diabetic subjects in parallel with improvements in insulin-stimulated glucose disposal. Despite a $67 \%$ increase, GLUT4 protein was not significantly altered in the obese non-diabetic group. This finding is similar to the GIR and reflects the variability within this group, even though subjects were matched for age and body weight. Thus, the increase in GLUT4 protein content in the type 2 diabetic subjects may explain the significant increase in glucose disposal following 7 days of exercise training. After 7 weeks of exercise training in type 2 diabetic subjects, GLUT4 protein content is increased and glycogen synthase fractional velocity is correlated with insulin-stimulated glucose storage [37]. GLUT4 cycling to the plasma membrane may have been increased in an AMPK-dependent manner to meet the increased demand for carbohydrate oxidation and storage. However, this does not fully explain the current findings. Despite the similar level of GLUT4 protein between groups, after 7 days of exercise training, the GIR of the type 2 diabetic group was still lower than the pre-exercise level in the obese nondiabetic group. Thus, in type 2 diabetic subjects there still appears to be a defect in insulin-responsive GLUT4 cycling to the plasma membrane that cannot be explained by muscle glycogen content alone. Indeed, we have previously reported that skeletal muscle cell surface GLUT4 content is reduced in type 2 diabetic subjects in response to either insulin or AICAR in vitro [49].

In conclusion, short-term exercise training increases insulin-mediated glucose disposal in obese type 2 diabetic subjects. The results from the present study indicate that the beneficial effects of exercise training on insulin action in 
skeletal muscle are related to changes in GLUT4 protein content and independent of improvements in signal transduction via several components of the canonical insulinsignalling cascade.

Acknowledgements This study was supported by a grant from the Irish Health Research Board, the Swedish Research Council, the Swedish Diabetes Association, the Foundation for Scientific Studies of Diabetology, the Strategic Research Foundation, the Swedish Centre for Sports Research, the Commission of the European Communities (Contract No LSHM-CT-2004-005272 EXGENESIS and Contract No LSHM-CT-2004-512013 EUGENE2). The authors would like to thank the staff of the Metabolic Research Unit and the Diabetes Day Centre at St James's Hospital for their assistance in data collection.

\section{References}

1. Cline GW, Petersen KF, Krssak M et al (1999) Impaired glucose transport as a cause of decreased insulin-stimulated muscle glycogen synthesis in Type 2 diabetes. N Engl J Med 341:240 246

2. Cusi K, Maezonon K, Osman A et al (2000) Insulin resistance differentially affects the PI3-kinase- and MAP kinase-mediated signalling in human muscle. J Clin Invest 105:311-320

3. Zierath JR, He L, Gumà A, Wahlström EO, Klip A, WallbergHenrikkson H (1996) Insulin action on glucose transport and plasma membrane GLUT4 content in skeletal muscle from patients with NIDDM. Diabetologia 39:1180-1189

4. Nuutila P, Koivisto VA, Knuuti J et al (1992) Glucose-free fatty acid cycle operates in human heart and skeletal muscle in vivo. J Clin Invest 89:1767-1774

5. Rothman DL, Magnusson I, Cline G et al (1995) Decreased muscle glucose transport/phosphorylation is an early defect in the pathogenesis of non-insulin-dependent diabetes mellitus. Proc Natl Acad Sci USA 92:983-987

6. Zierath JR, Krook A, Wallberg-Henriksson H (2000) Insulin action and insulin resistance in human skeletal muscle. Diabetologia 43:821-835

7. Dresner A, Laurent D, Marcucci M et al (1999) Effects of free fatty acids on glucose transport and IRS-1-associated phosphatidylinositol 3-kinase activity. J Clin Invest 103:253-259

8. Groop LC, Bonadonna RC, Del Prato S et al (1989) Glucose and free fatty acid metabolism in non-insulin-dependent diabetes mellitus. Evidence for multiple sites of insulin resistance. J Clin Invest 84:205-213

9. Bjornholm M, Kawano Y, Lehtihet M, Zierath JR (1997) Insulin receptor substrate-1 phosphorylation and phosphatidylinositol 3kinase activity in skeletal muscle from NIDDM subjects after in vivo insulin stimulation. Diabetes 46:524-527

10. Krook A, Björnholm M, Galuska D et al (2000) Characterization of signal transduction and glucose transport in skeletal muscle from Type 2 diabetic patients. Diabetes 49:284-292

11. Kim YB, Nikoulina SE, Ciaraldi TP, Henry RR, Kahn BB (1999) Normal insulin-dependent activation of Akt/protein kinase B, with diminished activation of phosphoinositide 3-kinase, in muscle in type 2 diabetes. J Clin Invest 104:733-741

12. Pedersen O, Bak JF, Andersen PH et al (1990) Evidence against altered expression of GLUT1 or GLUT4 in skeletal muscle of patients with obesity or NIDDM. Diabetes 39:865-870

13. Dela F, Larsen JJ, Mikines KJ, Ploug T, Petersen LN, Galbo H (1995) Insulin-stimulated muscle glucose clearance in patients with NIDDM: effects of one-legged physical training. Diabetes 44:1010-1020

14. Houmard JA, Shaw CD, Hickey MS, Tanner CJ (1999) Effect of short-term exercise training on insulin-stimulated PI3-kinase activity in human skeletal muscle. Am J Physiol 277:E1055E1060

15. Chibalin AV, Yu M, Ryder JW et al (2000) Exercise-induced changes in expression and activity of proteins involved in insulin signal transduction in skeletal muscle: differential effects in insulin-receptor substrates 1 and 2. Proc Natl Acad Sci USA 97:38-43

16. Kirwan JP, del Aguila LF, Williamson DL, O'Gorman DJ, Lewis RM, Krishnan RK (2000) Regular exercise enhances insulin activation of IRS-1 associated PI 3-kinase in human skeletal muscle. J Appl Physiol 88:797-803

17. $\mathrm{Yu} \mathrm{M,} \mathrm{Blomstrand} \mathrm{E,} \mathrm{Chibalin} \mathrm{AV,} \mathrm{Wallberg-Henriksson} \mathrm{H}$, Zierath JR, Krook A (2001) Exercise-associated differences in an array of proteins involved in signal transduction and glucose transport. J Appl Physiol 90:29-34

18. Cox JH, Cortright RN, Dohm GL, Houmard JA (1999) Effect of aging on response to exercise training in humans: skeletal muscle GLUT-4 and insulin sensitivity. J Appl Physiol 86:20192025

19. Gulve EA, Spina RJ (1995) Effect of 7-10 days of cycle ergometer exercise on skeletal muscle GLUT-4 protein content. J Appl Physiol 79:1562-1566

20. Phillips SM, Han X-X, Green HJ, Bonen A (1996) Increments in skeletal muscle GLUT-1 and GLUT-4 after endurance training in humans. Am J Physiol 270:E456-E462

21. Douen AG, Ramlal T, Rastog S et al (1990) Exercise induces recruitment of the 'insulin-responsive glucose transporter': evidence for distinct intracellular insulin- and exercise-recruitable transporter in skeletal muscle. J Biol Chem 265:1342713430

22. Dela F, Ploug T, Handberg A et al (1994) Physical training increases muscle GLUT4 protein and mRNA in patients with NIDDM. Diabetes 43:862-865

23. Tanner CJ, Koves TR, Cortright RL et al (2002) Effect of shortterm exercise training on insulin-stimulated PI3-kinase activity in middle aged men. Am J Physiol 282:E147-E153

24. Sano H, Kane S, Sano E et al (2003) Insulin-stimulated phosphorylation of a Rab GTPase-activating protein regulates GLUT4 translocation. J Biol Chem 278:14599-14602

25. Miinea CP, Sano H, Kane S et al (2005) AS160, the Akt substrate regulating GLUT4 translocation, has a functional Rab GTPase activating protein domain. Biochem J 391:87-93

26. Larance M, Ramm G, Stockli J et al (2005) Characterization of the role of the Rab GTPase-activating protein AS160 in insulin-regulated GLUT4 trafficking. J Biol Chem 280:3780337813

27. Zeigerer A, McBrayer MK, McGraw TE (2004) Insulin stimulation of GLUT4 exocytosis, but not its inhibition of endocytosis, is dependent on RabGAP AS160. Mol Biol Cell $15: 4406-4415$

28. Bruss MD, Arias EB, Lienhard GE, Cartee GD (2005) Increased phosphorylation of Akt substrate of $160 \mathrm{kDa}$ (AS160) in rat skeletal muscle in response to insulin or contractile activity. Diabetes 54:41-50

29. Bogardus C, Thuillez P, Ravussin E, Vasquez B, Narimiga M, Azhar S (1983) Effect of muscle glycogen depletion on in vivo insulin action in man. J Clin Invest 72:1605-1610

30. O'Gorman DJ, del Aguila LF, Williamson DL, Krishnan RK, Kirwan JP (2000) Insulin and exercise differentially regulate IRS1-associated PI3-kinase and glycogen synthase in human skeletal muscle during immediate recovery from exercise. J Appl Physiol 89:1412-1419 
31. Kennedy JW, Hirshman MF, Gervino EV et al (1999) Acute exercise induces GLUT4 translocation in skeletal muscle of normal human subjects and subjects with type 2 diabetes. Diabetes 48:1192-1197

32. Price TB, Rothman DL, Taylor R, Avison MJ, Shulman GI, Shulman RG (1994) Human muscle glycogen resynthesis after exercise: insulin-dependent and -independent phases. J Appl Physiol 76:104-111

33. Devlin JT, Horton ES (1985) Effects of prior high intensity exercise on glucose metabolism in normal and insulin-resistant men. Diabetes 34:973-979

34. Perseghin G, Price TB, Petersen KF et al (1996) Increased glucose transport-phosphorylation and muscle glycogen synthesis after exercise training in insulin-resistant subjects. $N$ Engl J Med 335:1357-1362

35. Ross R, Janssen I, Dawson J et al (2004) Exercise-induced reduction in obesity and insulin resistance in women: a randomized controlled trial. Obes Res 12:789-798

36. Dela F, Mikines KJ, Sonne B, Glabo H (1994) Effect of training on interaction between insulin and exercise in human muscle. J Appl Physiol 76:2386-2393

37. Christ-Roberts CY, Pratipanawatr T, Pratipanawatr W et al (2004) Exercise training increases glycogen synthase activity and GLUT4 expression but not insulin signalling in overweight nondiabetic and type 2 diabetic subjects. Metabolism 53:1233-1242

38. Higaki Y, Wojtaszewski JFP, Hirshman MF et al (1999) Insulin receptor substrate-2 is not necessary for insulin- and exercisestimulated glucose transport in skeletal muscle. J Biol Chem 274:20791-20795

39. Ahmad F, Azevedo JL, Cortright R, Dohm GL, Goldstein BJ (1997) Alterations in skeletal muscle protein-tyrosine phosphatase activity and expression in insulin-resistant human obesity and diabetes. J Clin Invest 100:449-458

40. Kosaki A, Yaamada K, Suga J, Otaka A, Kuzuya H (1998) 14-3$3 \beta$ protein associates with insulin receptor substrate 1 and decreases insulin-stimulated phosphatidylinositol 3'-kinase activity in 3T3L1 adipocytes. J Biol Chem 273:904-944
41. Christ CY, Hunt D, Hancock J, Garcia-Macedo R, Mandarino LJ, Ivy JL (2002) Exercise training improves muscle insulin resistance but not insulin receptor signalling in obese Zucker rats. J Appl Physiol 92:736-744

42. Staubs PA, Nelson JG, Reichart DR, Olefsky JM (1998) Plateletderived growth factor inhibits insulin stimulation of insulin receptor substrate-1-associated phosphatidylinositol 3-kinase in 3T3-L1 adipocytes without affecting glucose transport. J Biol Chem 273:25139-25147

43. Sharma PM, Egawa K, Gustafson TA, Martin JL, Olefsky JM (1997) Adenovirus-mediated overexpression of IRS-1 interacting domains abolishes insulin-stimulated mitogenesis without affecting glucose transport in 3T3-L1 adipocytes. Mol Cell Biol 17:7386-7397

44. Deshmukh A, Coffey VG, Ahong Z, Chibalin AV, Hawley JA, Zierath JR (2006) Exercise-induced phosphorylation of the novel Akt substrates AS160 and Filamin in human skeletal muscle. Diabetes 55:1776-1782

45. Treebak JT, Glund S, Deshmukt A et al (2006) AMPK-mediated AS160 phosphorylation in skeletal muscle is dependent on AMPK catalytic and regulatory subunits. Diabetes 55:2051-2058

46. Karlsson HKR, Zierath JR, Kane S, Krook A, Lienhard GE, Wallberg-Henriksson H (2005) Insulin-stimulated phosphorylation of the Akt substrate AS160 is impaired in skeletal muscle of type 2 diabetic subjects. Diabetes 54:1692-1697

47. Karlsson HKR, Hallsten K, Bjornholm M et al (2005) Effects of metformin and rosiglitazone treatment on insulin signalling and glucose uptake in patients with newly diagnosed type 2 diabetes. Diabetes 54:1459-1467

48. Wadley GD, Tunstall RJ, Sanigorski A, Collier GR, Hargreaves M, Cameron-Smith D (2001) Differential effects of exercise on insulin-signalling gene expression in human skeletal muscle. J Appl Physiol 90:436-440

49. Koistinen HA, Galuska D, Chibalin AV et al (2003) 5-Aminoimidazole carboxamide riboside increases glucose transport and cell-surface GLUT4 content in skeletal muscle from subjects with type 2 diabetes. Diabetes 52:1066-1072 